\title{
Plasminogen activation by staphylokinase enhances local spreading of $S$. aureus in skin infections
}

\author{
Marijke Peetermans ${ }^{1 *}$, Thomas Vanassche ${ }^{1}$, Laurens Liesenborghs ${ }^{1}$, Jorien Claes ${ }^{1}$, Greetje Vande Velde ${ }^{2}$, \\ Jakub Kwiecinksi ${ }^{3}$, Tao Jin $^{3}$, Bart De Geest ${ }^{1}$, Marc F Hoylaerts ${ }^{1}$, Roger H Lijnen ${ }^{1}$ and Peter Verhamme ${ }^{1}$
}

\begin{abstract}
Background: Staphylococcus aureus (S. aureus) is a frequent cause of skin and soft tissue infections. A unique feature of $S$. aureus is the combined presence of coagulases that trigger fibrin formation and of the plasminogen activator staphylokinase (SAK). Whereas the importance of fibrin generation for $S$. aureus virulence has been established, the role of SAK remains unclear.

We studied the role of plasminogen activation by SAK in a skin infection model in mice and evaluated the impact of alpha-2-antiplasmin ( $\mathrm{a}_{2} \mathrm{AP}$ ) deficiency on the spreading and proteolytic activity of $\mathrm{S}$. aureus skin infections. The species-selectivity of SAK was overcome by adenoviral expression of human plasminogen. Bacterial spread and density was assessed non-invasively by imaging the bioluminescence of S. aureus Xen36.
\end{abstract}

Results: SAK-mediated plasmin activity increased the local invasiveness of S. aureus, leading to larger lesions with skin disruption as well as decreased bacterial clearance by the host. Even though fibrin and bacterial surfaces protected SAK-mediated plasmin activity from inhibition by $a_{2} A P$, the deficiency of $a_{2} A P$ resulted in increased bacterial spreading. SAK-mediated plasmin also induced secondary activation of gelatinases, shown both in vitro and in lesions from the in vivo model.

Conclusion: SAK contributes to the phenotype of S. aureus skin infections by enhancing bacterial spreading as a result of fibrinolytic and proteolytic activation.

Keywords: Fibrinolysis, Matrix metalloproteinases, Plasminogen, Staphylococcus aureus, Staphylokinase, Skin infection

\section{Background}

Staphylococcus aureus (S. aureus) is the leading cause of skin and soft tissue infections, both community- and hospital-acquired $[1,2]$. S. aureus is a versatile pathogen that has the intriguing capacity to modulate both the host's coagulation and fibrinolytic system.

We and others have shown that fibrin formation induced by the bacterial prothrombin activators staphylocoagulase and von Willebrand factor-binding protein is an important virulence factor for both localized and systemic infections by $S$. aureus and is essential for abscess formation [3-6]. Most S. aureus strains causing infection

\footnotetext{
* Correspondence: marijke.peetermans@med.kuleuven.be

${ }^{1}$ Center for Molecular and Vascular Biology, KU Leuven, Herestraat 49, Box 911, Leuven, Belgium

Full list of author information is available at the end of the article
}

in humans also produce staphylokinase (SAK). SAK forms an equimolar complex with human plasmin (huPli) catalyzing the further activation of plasminogen. The SAKhuPli complex is sensitive to rapid inhibition by alpha-2antiplasmin $\left(\alpha_{2} \mathrm{AP}\right)$ unless it is bound to fibrin via the lysine binding sites of plasmin. This mechanism accounts for the fibrin-specificity of SAK $[7,8]$. Although SAK has received considerable research attention during its development as a fibrinolytic agent in cardiovascular medicine [7], few studies have investigated its relevance in S. aureus infection $[9,10]$.

Streptokinase, secreted by group A, C and G streptococci, is the other well-known bacterial plasminogen activator. Like SAK, streptokinase is specific for human plasminogen (huPlg) but its action is not inhibited by $\alpha_{2} \mathrm{AP}$ [11]. Streptokinase is a key virulence factor and the 
primary determinant of the species-selectivity of group A streptococcal infections. Mortality after infection with group A streptococci is markedly increased in huPlg transgenic mice [12,13]. Interestingly, a subcluster of streptokinase (type 2b) has been identified that is sensitive to $\alpha_{2} \mathrm{AP}$ inhibition, leading to site-restricted plasminogen activation in these, mostly skin-trophic, group A streptococci [14].

The role of SAK as a potential virulence factor in $S$. aureus disease remains unresolved. SAK is present in the large majority of $S$. aureus strains causing human infection [15-24]. In contrast, S. aureus strains from veterinary sources commonly lack SAK production [23,24]. SAK, like streptokinase [25], thus constitutes an adaptation of S. aureus for human infection. The sak gene has a highly conserved sequence [26-29] and is carried on a bacteriophage containing other genes with an important function in immune evasion, such as complement inhibitory factors and enterotoxins $[21,30]$. SAK was shown to enhance the breaching of tissue barriers in vitro [10].

The present study aimed at evaluating if plasmin generation by SAK impacts on proteolytic activity in S. aureus infected skin and on the local and systemic dissemination of $S$. aureus. We further investigated if the host $\alpha_{2} \mathrm{AP}$, by inhibiting the SAK-plasmin activity, reduces the virulence of $S$. aureus.

\section{Results}

\section{Bacterial staphylokinase production}

Supernatant of overnight cultures of the bioluminescent $S$. aureus Xen36 contained similar levels of SAK compared to lab strains and to clinical $S$. aureus strains from skin infection and from bacteremia with cutaneous origin. SAK expression by LS-1 spasak, which expresses SAK under the control of the protein $A$ promoter, was about tenfold higher (Figure 1). Thus, S. aureus Xen36 is a relevant micro-organism to study the role of SAK in a skin infection model.

\section{Skin infection model}

\section{Adenoviral-mediated human plasminogen expression}

To overcome the species-selectivity of SAK for huPlg, huPlg was expressed in mice through adenoviral gene transfer. Seven to 11 days after adenoviral injection, i.e. at the start of the subcutaneous infection experiment, huPlg plasma values in Adplasm injected mice were $31.6 \pm 15.5 \mu \mathrm{g} / \mathrm{ml}$ in $\alpha_{2} \mathrm{AP} \mathrm{KO}$ and $31.5 \pm 10.1 \mu \mathrm{g} / \mathrm{ml}$ in $\alpha_{2} \mathrm{AP}$ WT mice. In mice injected with the control Adnull adenoviral vector, values of huPlg were below the detection level $(3 \mu \mathrm{g} / \mathrm{ml})$. Human plasminogen remained present until the end of the experiment $(27.3 \pm 10.0 \mu \mathrm{g} / \mathrm{ml}$ at day 5 and $37.2 \pm 29.6 \mu \mathrm{g} / \mathrm{ml}$ at day 10) (Figure 2). Hence, the expression of huPlg allowed for the selective interaction of SAK with huPlg throughout the course of the subcutaneous infection experiment.

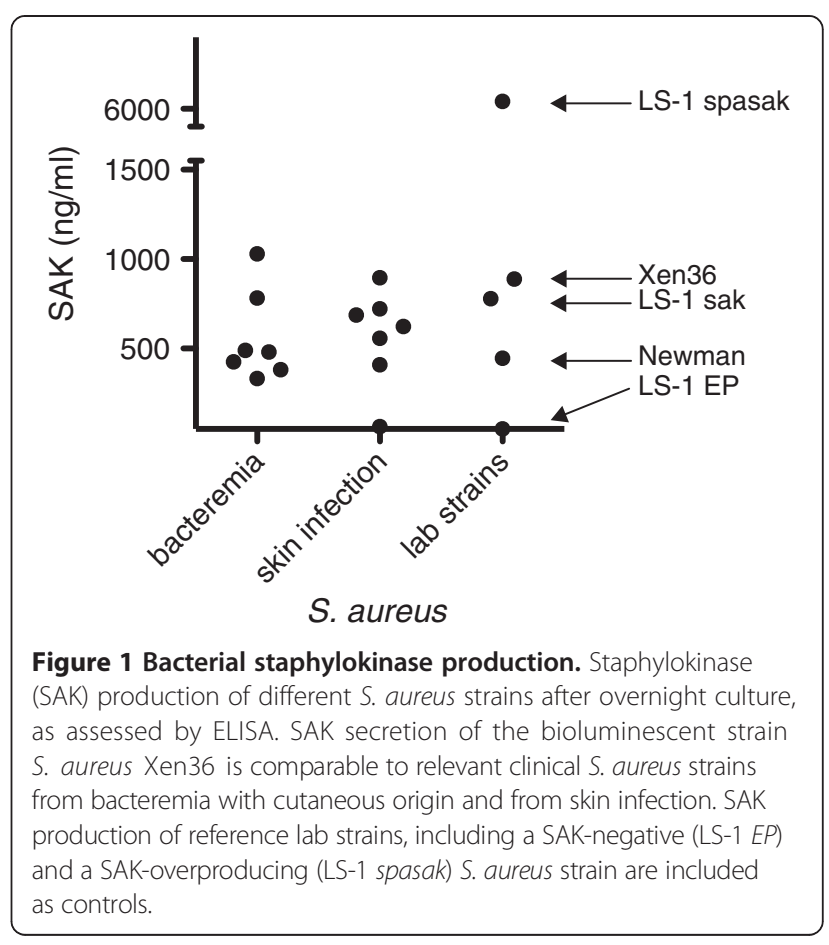

\section{Infectious skin lesions}

After subcutaneous inoculation with $S$. aureus Xen36, macroscopic lesion size was significantly larger in huPlg expressing mice compared to control wild type mice $\left(33.6 \pm 19.6 \mathrm{~mm}^{2}\right.$ in $\mathrm{WT} /$ huPlg mice $(\mathrm{n}=17)$ vs. $19.2 \pm$ $9.7 \mathrm{~mm}^{2}$ in WT/null mice $(\mathrm{n}=12)$ at day $\left.10, \mathrm{P}<0.01\right)$ (Figure 3A). The constitutive luciferase expression of $S$. aureus Xen36 also allowed for non-invasive monitoring of the spreading and density of the bacteria over time (illustrated in Figure 3C). Expression of huPlg increased both bacterial spreading $(\mathrm{P}<0.05$ on day $3, \mathrm{P}<0.01$ on day 6 and 9$)$ and bacterial load $(\mathrm{P}<0.05$ on day 3 and $9, \mathrm{P}<0.01$ on day 6 ) early in the course of infection (Figures 3B and 3D).

Compared to wild type mice, bacterial spreading in $\alpha_{2} \mathrm{AP}$ KO mice was similar in the early stages of the infection, but was more pronounced at day $9(\mathrm{P}<0.05)$ (Figure $3 \mathrm{~B}$ ), resulting in an increase in macroscopic lesion size at day $10\left(31.8 \pm 20.9 \mathrm{~mm}^{2}\right.$ in $\alpha_{2} \mathrm{AP} \mathrm{KO} /$ null mice $(n=11)$ vs. $19.2 \pm 9.7 \mathrm{~mm}^{2}$ in WT/null mice $(\mathrm{n}=12)$, $\mathrm{P}=0.078$ ) (Figure 3A). Bacterial density was higher in $\alpha_{2} \mathrm{AP}$ KO mice compared to wild type mice ( $\mathrm{P}=0.115$ on day $6, \mathrm{P}<0.05$ on day 9 ) (Figure $3 \mathrm{D}$ ). In an additional experiment, $\alpha_{2} \mathrm{AP}$ KO or WT mice were infected with $S$. aureus LS-1 EP. We observed similar initial fibrin deposition in the abscess periphery in both groups at day 1 (Additional file 1), consistent with a normal capacity for fibrin formation in $\alpha_{2} \mathrm{AP} \mathrm{KO}$ plasma ex vivo (data not shown). However, at a later time point, less fibrin was observed in $\alpha_{2} \mathrm{AP}$ KO mice, as shown in Additional file 1. 


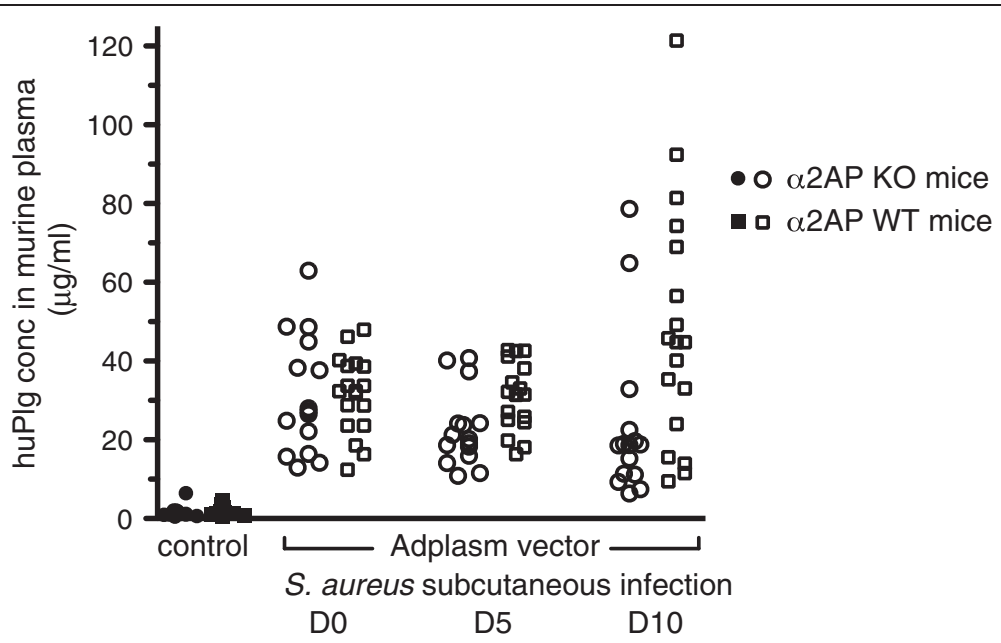

Figure 2 Adenoviral-mediated human plasminogen expression. Human plasminogen (huPlg) expression in murine plasma after administration of $5 \times 10^{10}$ viral particles of adenoviral vector Adplasm. Day 0 is the day of subcutaneous infection with S. aureus Xen36, 7 to 11 days after adenoviral injection. Values from Adnull injected mice are included as negative controls. The expression of huPlg during the whole course of the subcutaneous infection experiment allows the selective interaction of staphylokinase with huPlg.

The largest lesion size was observed in the $\alpha_{2} \mathrm{AP}$ KO mice with human plasminogen expression $\left(42.9 \pm 27.4 \mathrm{~mm}^{2}\right.$ in $\alpha_{2} \mathrm{AP} \mathrm{KO} / \mathrm{huPlg}(\mathrm{n}=14)$ vs. $19.2 \pm 9.7 \mathrm{~mm}^{2}$ in $\mathrm{WT} /$ null $(n=12), P<0.001)$ (Figure 3A). The spreading of the bacteria was more pronounced from early in the course of infection $(\mathrm{P}=0.137$ on day $3, \mathrm{P}<0.01$ on day 6 and 9$)$ (Figure 3B). Also the intensity of the bioluminescence, which relates to the bacterial density, was the highest in the $\alpha_{2} \mathrm{AP} \mathrm{KO} / \mathrm{huPlg}$ group $(\mathrm{P}=0.153$ on day $3, \mathrm{P}<0.01$ on day $6, \mathrm{P}<0.05$ on day 9) (Figure $3 \mathrm{D}$ ).

The assessment of systemic spread of $S$. aureus, by quantifying bacterial load in spleen and kidney, did not differ significantly between the 4 groups. At day 10 , there were 2 mice in the $\alpha_{2} \mathrm{AP} \mathrm{KO} / \mathrm{huPlg}$ group with distant infection in spleen and/or kidney, 2 mice in the $\alpha_{2} \mathrm{AP} \mathrm{KO} /$ null group, 1 mouse in the WT/huPlg group and none in the WT/null group.

In the first series of experiments, we observed that the differentiation between the groups both in macroscopic phenotype (open/closed lesion) and in bioluminescence lesion size and intensity became apparent early in the course of infection. Therefore, to assess macroscopic and microscopic phenotype and proteolytic activity, mice were sacrificed at day 3 in a subsequent set of experiments.

Macroscopical assessment confirmed closed abscesses in WT/null mice, compared to more diffusely spread lesions with skin rupture in huPlg expressing mice $(\mathrm{P}<0.01)$ (Figure 4A-C).

Histopathologic analysis of lesional skin sections from $\alpha_{2} \mathrm{AP} \mathrm{KO} / \mathrm{huPlg}$ mice showed, apart from breaching of skin, penetration of infection starting from the initial infection site, past a peripheral fibrin zone, into subdermal tissue layers (Figure 4C-E).

\section{Mechanism of SAK action in S. aureus skin infections} SAK is species-selective and fibrin-specific

The observations in the subcutaneous infection model can be explained by the SAK-mediated plasmin generation. To this end however, the values of huPlg achieved after adenoviral huPlg expression in mice, should be able to rescue the species-selectivity of SAK in a murine model. SAK induced rapid plasmin generation if added to huPlg but not with murine plasminogen (muPlg) (Figure 5A). However, activation of muPlg was observed in the presence of SAK and trace amounts of human plasminogen (Figure 5A). Also, addition of a preformed SAK-huPli complex triggered secondary activation of muPlg, as illustrated in Figure 5B. For all further experiments, a mixture of muPlg $(0.25 \mu \mathrm{M})$ and huPlg $(0.05 \mu \mathrm{M})$ was used to reflect the in vivo conditions of partial huPlg expression against a background of muPlg.

SAK-mediated plasmin generation was further enhanced in the presence of fibrin, as $\mathrm{CnBr}$-digested fibrinogen fragments $(\mathrm{Fg}(\mathrm{CNBr}))$ (Figure $5 \mathrm{C}-\mathrm{D})$ or as solid fibrin (data not shown). For convenience, $\mathrm{Fg}(\mathrm{CNBr})$ was used in further experiments, as an accepted soluble alternative to solid fibrin. This increase in plasmin generation in the presence of fibrin can be explained by a reduced inactivation of fibrin-associated SAK-huPli complex by $\alpha_{2}$ AP. As shown in Figure 5C, $\alpha_{2} \mathrm{AP}$ inhibited SAK-induced plasmin generation in control conditions, but had little effect on SAK-induced plasmin generation in the presence of $\mathrm{Fg}(\mathrm{CNBr})\left(\mathrm{A}_{405,60 \mathrm{~min}}\right.$ of $0.853 \pm 0.058$ vs. $0.121 \pm 0.005$ for $\left.\mathrm{SAK}+\mathrm{Plg}+\alpha_{2} \mathrm{AP}, \quad \mathrm{P}<0.01\right)$. Higher concentrations of $\mathrm{Fg}(\mathrm{CNBr})$ completely protected SAK-induced plasmin from inhibition by $\alpha_{2} \mathrm{AP}\left(\mathrm{A}_{405}, 60 \mathrm{~min}\right.$ of $1.036 \pm 0.039$ vs. $0.121 \pm 0.005$ for $\mathrm{SAK}+\mathrm{Plg}+\alpha_{2} \mathrm{AP}, \mathrm{P}<0.001$ ) (Figure $5 \mathrm{D}$ ). 


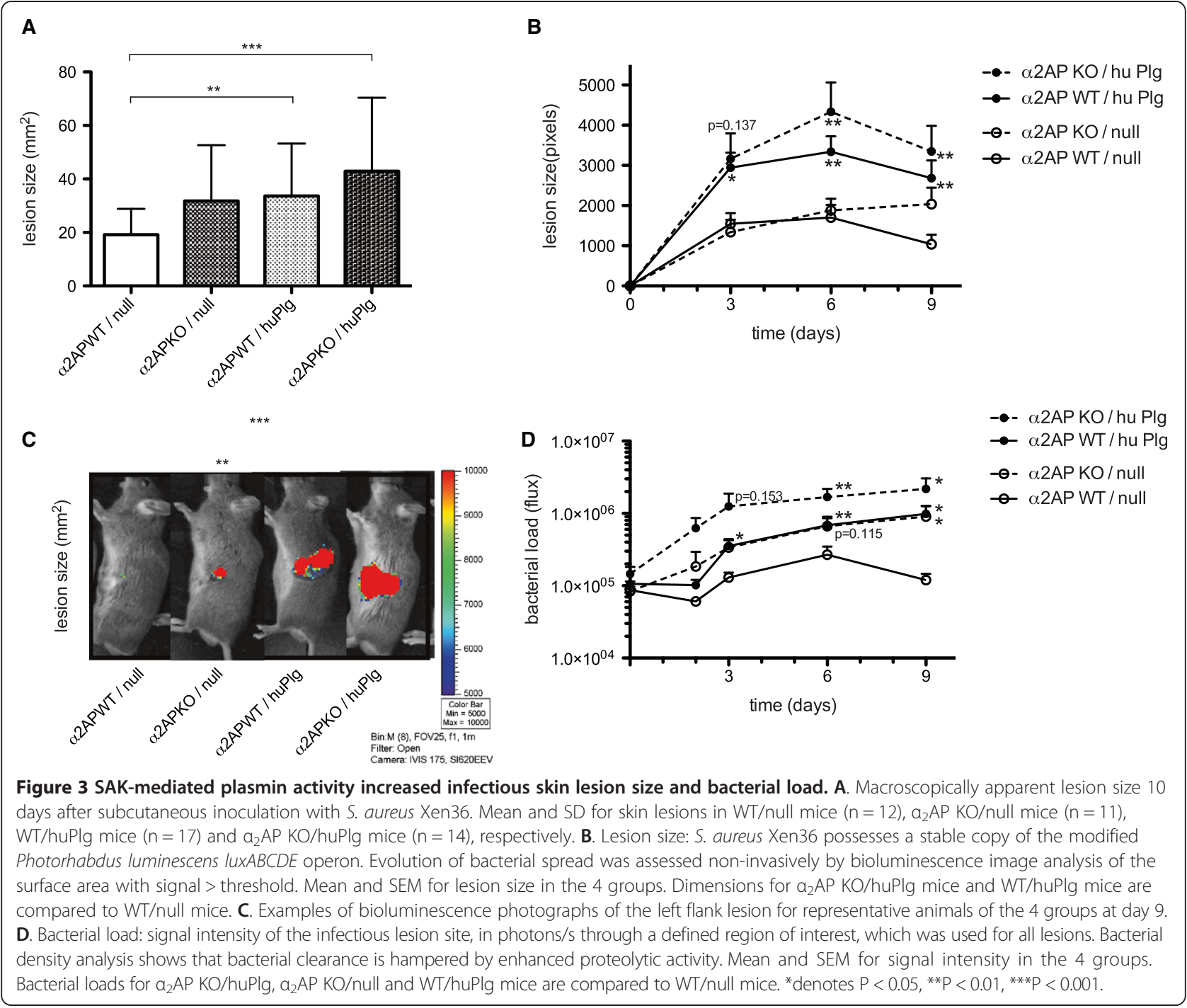

\section{Bacterial cell surface protects $S A K$ from $a_{2} A P$ inhibition}

We also studied if, besides fibrin, bacterial surfaces could protect the SAK-huPli complex from $\alpha_{2} \mathrm{AP}$ inhibition. Indeed, the presence of bacteria increased plasmin generation following addition of SAK $\left(\mathrm{A}_{405}, 90 \mathrm{~min} 1.035 \pm\right.$ 0.076 vs. $0.675 \pm 0.138, \mathrm{P}<0.05)$. Addition of murine $\alpha_{2} \mathrm{AP}$ significantly reduced plasmin generation by $\approx 70 \%$ to $\mathrm{A}_{405}$, 90min of $0.195 \pm 0.034(\mathrm{P}<0.05)$, whereas in the presence of bacteria, $\alpha_{2} \mathrm{AP}$ only led to $\mathrm{a} \approx 50 \%$ reduction in plasmin generation $\left(\mathrm{A}_{405}, 90 \mathrm{~min}=0.487 \pm 0.094\right.$, $\mathrm{P}<0.01$ ) (Figure 6). We used a SAK-negative $S$. aureus strain (LS-1 EP) for this subset of experiments to eliminate confounding by SAK production during the course of the experiment. However, similar results were observed for SAK-positive S. aureus Xen36, which was the strain used in animal experiments. Comparable results were also obtained when heat-killed instead of viable $S$. aureus was used (data not shown).

\section{SAK-huPli complex activates gelatinases}

Plasmin has a broad proteolytic spectrum that includes extracellular matrix proteins. However, plasmin is also known to activate gelatinases, which can cause secondary proteolytic activity. In order to assess whether gelatinase activation contributes to the observed bacterial spreading, we measured the activation of gelatinases by SAK-huPli in murine skin extracts.

Addition of SAK and huPlg to extracts of murine skin led to activation of pro-MMP-2 (Figure 7A). In line with the low expression of MMP-9 in normal non-inflamed skin, pro-MMP-9 and active MMP-9 could not be clearly identified on these zymograms of murine skin. However, we did observe MMP-9 activation in HT1080 cell culture supernatant after incubation with SAK and huPlg (data not shown).

Zymograms of day 3 lesions (2 representative lesions per group) showed a higher ratio of active/total MMP-2 


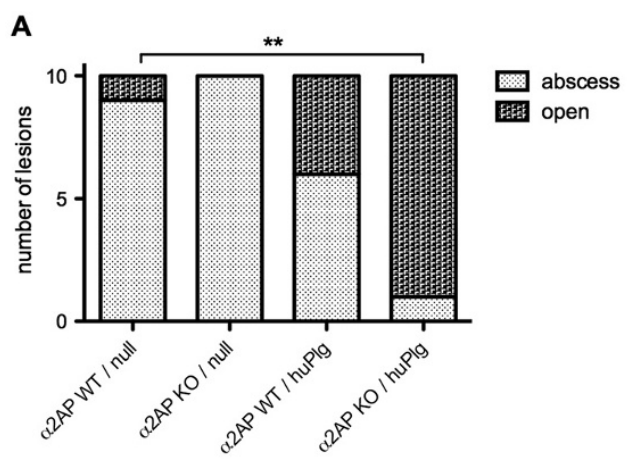

B

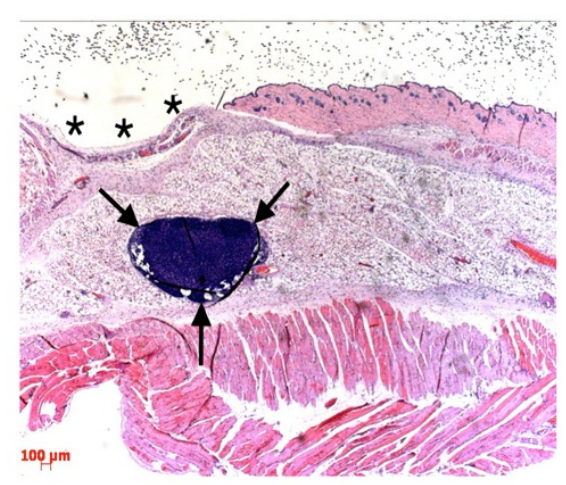

C

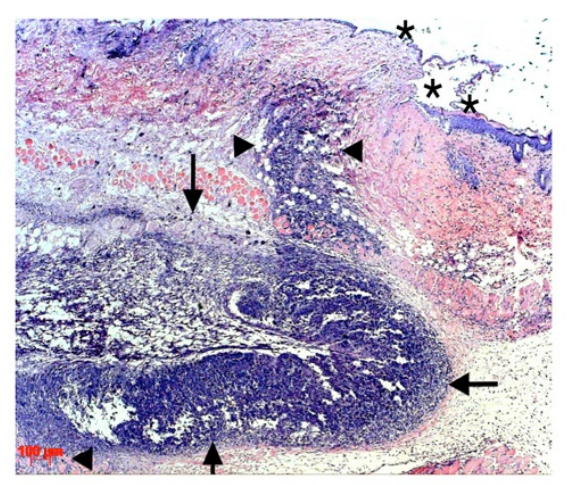

D

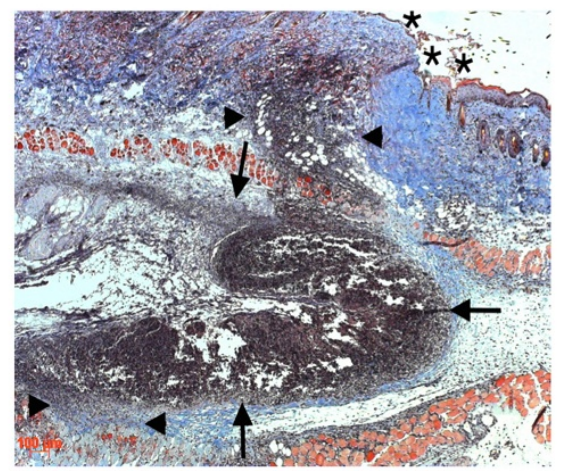

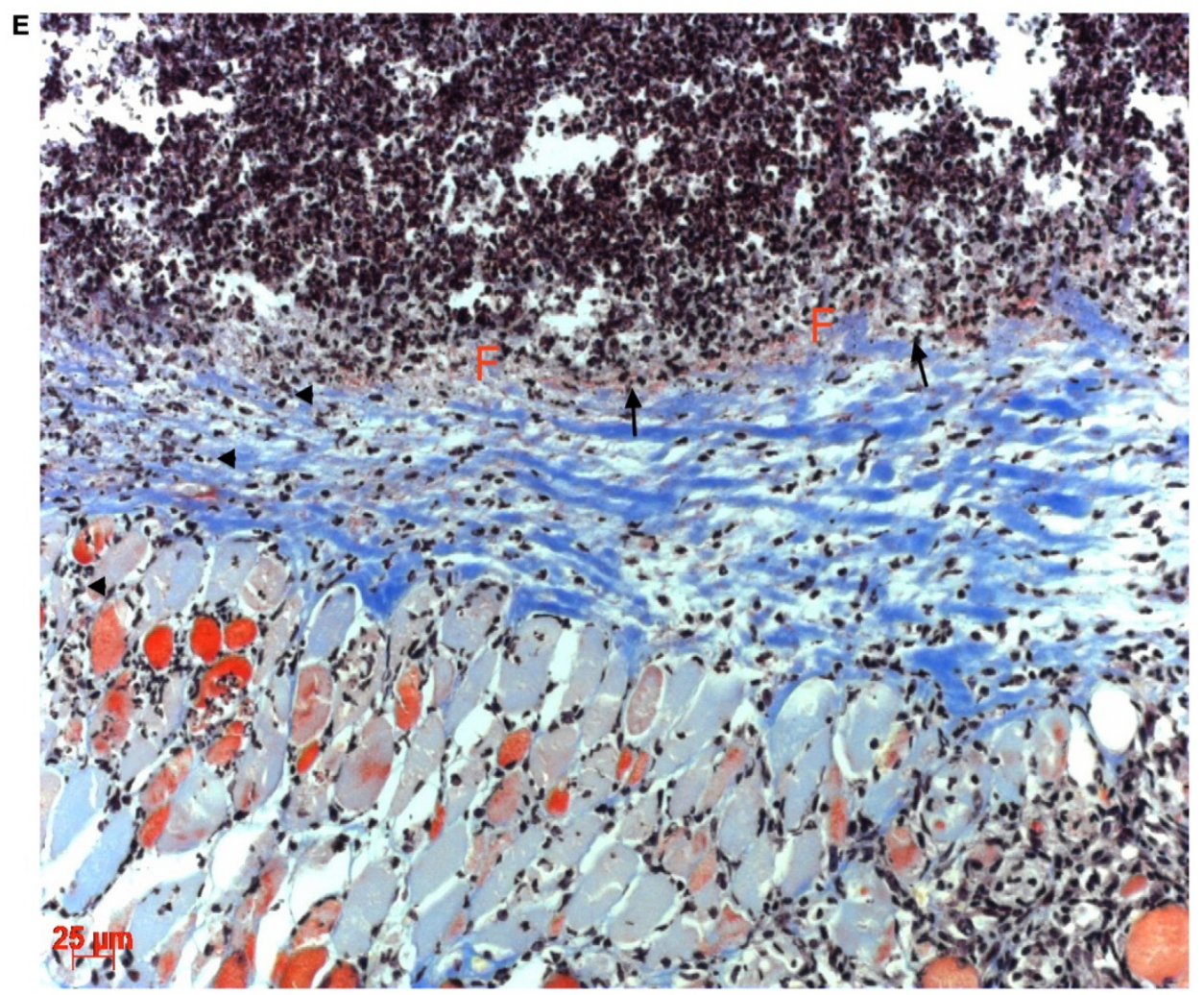

Figure 4 (See legend on next page.) 
(See figure on previous page.)

Figure 4 Infectious skin lesions at day 3 after subcutaneous infection with S. aureus Xen36. A. Macroscopic aspect of day 3 lesions. More open lesions with skin rupture are observed in $\mathrm{a}_{2} \mathrm{AP} \mathrm{KO} / \mathrm{huPlg}$ mice, compared to WT/null mice $(P<0.01)$. B. Hematoxyllin-eosin staining of lesional skin from WT/null mouse showing a small abscess collection (arrows) without disruption of overlying skin (*). C. Hematoxyllin-eosin staining of lesional skin from $\mathrm{a}_{2} \mathrm{AP} \mathrm{KO} /$ huPlg mouse showing a large, less well-defined abscess collection (arrows), with extension (arrowheads) from the initial infection site both towards the overlying skin $\left(^{*}\right.$ ) (with resulting skin disruption and crust formation) and towards the underlying subdermal tissue and muscularis. D-E. Martius Scarlet Blue staining of the same lesion reveals a zone of fibrin deposition (F, red) at the periphery of the initial abscess site (arrows), but the infection has spread past this border of fibrin, through collagen fibers (blue), into underlying tissue layers (arrowheads).

in $\alpha_{2} \mathrm{AP} \mathrm{KO} / \mathrm{huPlg}$ mice, compared to control WT/null mice (Figure 7B). Increased MMP-9 expression and activity was observed in all infected skins compared to normal skin, with a similar higher ratio of active/total MMP-9 in the $\alpha_{2} \mathrm{AP} \mathrm{KO} / \mathrm{huPlg}$ group compared to control WT/null mice (Western blot, Figure 7C).

\section{Discussion}

We evaluated the role of SAK-mediated plasminogen activation in a subcutaneous $S$. aureus skin infection model in mice. Our results demonstrate that plasmin generation by SAK increased spreading and hampered bacterial clearance of $S$. aureus in infected skin, increased tissue proteolytic MMP activity, and resulted in more pronounced tissue damage, as noted by more open skin lesions. These findings were enhanced in the absence of the plasmin inhibitor $\alpha_{2} \mathrm{AP}$, demonstrating a role for host $\alpha_{2} \mathrm{AP}$ in the containment of $S$. aureus infections.

Strengths of our model are the use of a S. aureus strain derived from a human infection in healthy mice, and the non-invasive follow-up of bacterial spreading by bioluminescence. The use of an adenoviral vector encoding huPlg resulted in plasma huPlg levels similar to those attained in transgenic huPlg mice [12]. Our in vitro data confirm that these huPlg concentrations in mice are sufficient to overcome the species-selectivity of SAK and to mimic the phenotype of SAK-mediated huPlg activation in the subcutaneous infection model.

Our results are in line with previous results showing that spreading through tissue barriers can be mediated
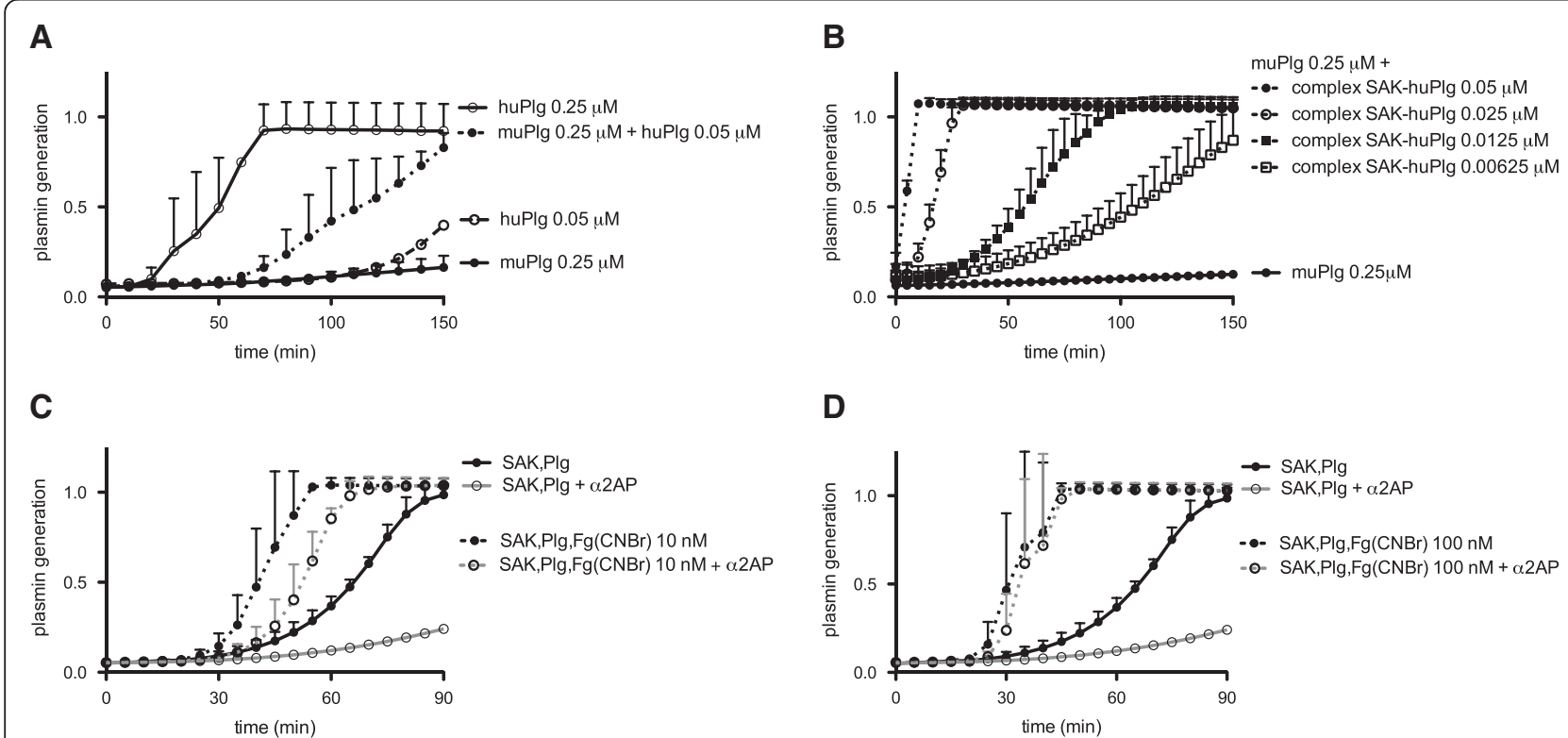

Figure 5 Species-selectivity and fibrin-specificity of staphylokinase. A. Species-selectivity of staphylokinase (SAK) for human plasminogen (huPlg). Plasmin generation by adding SAK $(6.25 \mathrm{nM})$ to either huPlg $(0.25 \mu \mathrm{M})$, murine plasminogen (muPlg $0.25 \mu \mathrm{M}$ ), or a mixture of muPlg $(0.25 \mu \mathrm{M})$ with huPlg $(0.05 \mu \mathrm{M}$ or $20 \%$ of the muPlg concentration, comparable to the level of huPlg in murine plasma after adenoviral-mediated huPlg expression). Plasmin generation was quantitated by conversion of the chromogenic substrate S-2403 and assessed in a microtiter plate ELISA reader at $405 \mathrm{~nm}$. Mean and SD from 3 independent experiments. B. Plasmin generation by a preformed equimolar mixture of SAK with huPlg, added to muPlg $(0.25 \mu \mathrm{M})$, highlighting that low levels of huPlg in a background of muPlg can induce efficient SAK-dependent plasmin generation. Mean and SD from 3 independent experiments. C-D. The complex of SAK with human plasmin (SAK-huPli) is protected from inhibition by alpha-2-antiplasmin $\left(\mathrm{a}_{2} \mathrm{AP}\right)$ in the presence of fibrin analogues. Plasmin generation by SAK (6.25 $\left.\mathrm{nM}\right)$ in a mixture of muPlg $(0.25 \mu \mathrm{M})$ and huPlg $(0.05 \mu \mathrm{M})$; with or without $\mathrm{a}_{2} \mathrm{AP}(0.125 \mu \mathrm{M})$ and either in the absence or presence of $\mathrm{Fg}(\mathrm{CNBr})(\mathbf{C}$. and $\mathbf{D}$. for Fg (CNBr) $10 \mathrm{nM}$ and $100 \mathrm{nM}$, respectively). Mean and SD from 3 independent experiments. 


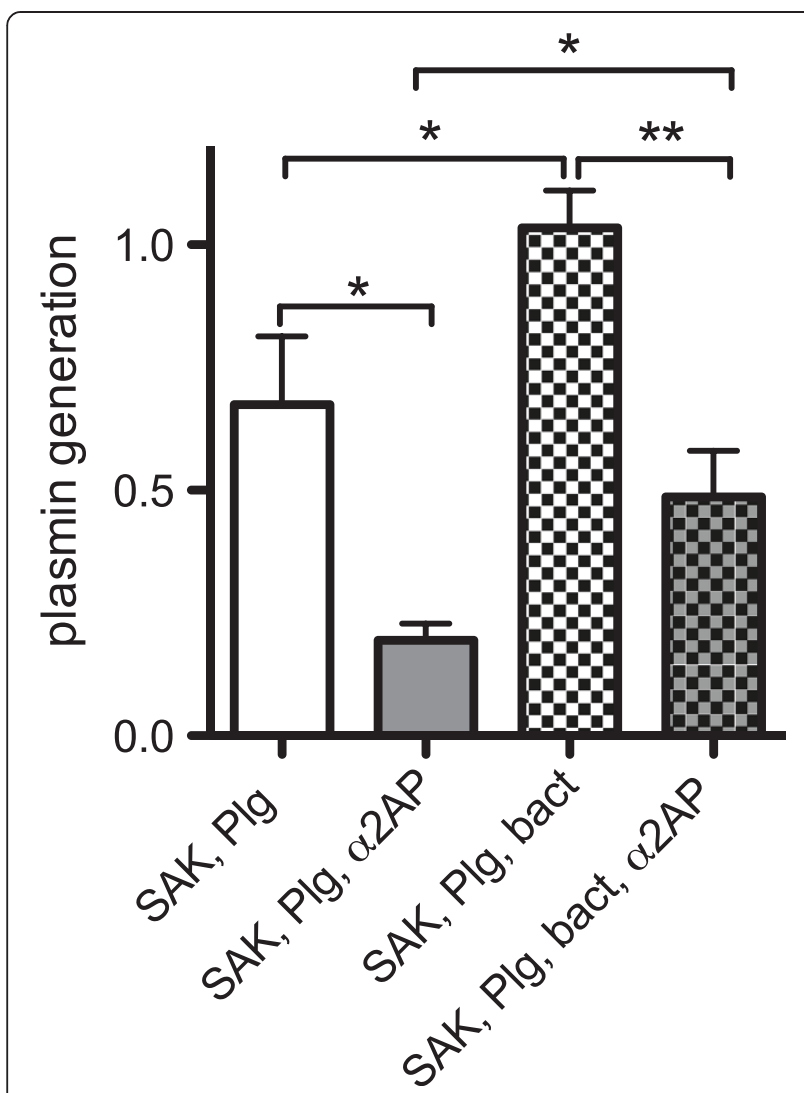

Figure 6 SAK-huPli complex is protected from inhibition by $a_{2} A P$ in the presence of $S$. aureus bacterial surfaces. $S$. aureus bacterial surfaces enhance SAK-mediated plasmin generation and partially protect the SAK-huPli complex from inhibition by $a_{2}$ AP. Plasmin generation by SAK $(6.25 \mathrm{nM})$ in a mixture of murine $(0.25 \mu \mathrm{M})$ and human $(0.05 \mu \mathrm{M})$ plasminogen, with or without $\mathrm{a}_{2} \mathrm{AP}(0.125 \mu \mathrm{M})$ and in the absence or presence of washed SAK-negative $S$. aureus LS-1 EP $\left(\mathrm{OD}_{600} 2.0,15 \% \mathrm{vol} / \mathrm{vol}\right)$. Plasmin generation was quantitated by conversion of the chromogenic substrate S-2403 and assessed in a microtiter plate ELISA reader at $405 \mathrm{~nm}$. Mean and SD from 3 independent experiments. ${ }^{*}$ denotes $P<0.05,{ }^{* *} P<0.01$.

by SAK activity [10]. Plasmin activity generated by SAK can degrade several extracellular matrix components, but not collagens [31]. Yet, we show that SAK-mediated plasmin activity can lead to secondary activation of gelatinases in mouse skin extracts, which may contribute to the proteolytic activity necessary for dissemination through tissue.

Although we observed more proteolytic activity and increased lesion dimensions in $\alpha_{2} \mathrm{AP} \mathrm{KO} / \mathrm{huPlg}$ groups, we did not observe systemic spread nor mortality after subcutaneous inoculation of $S$. aureus. However, systemic dissemination was common when using a neutropenic mouse model of $S$. aureus skin infection, as recently shown [10]. This is in agreement with the clinical observation that skin infections by $S$. aureus infrequently lead to systemic dissemination, unless there is an underlying vulnerability of the patient. In immunocompetent mice (and patients), staphylococcal skin and soft tissue infections are mainly characterized by abscess formation, and bacteria that do reach the systemic circulation or distant organs are rapidly cleared.

The predominantly local effect of SAK-mediated plasmin activity without affecting the severity of systemic symptoms is also in contrast with the findings by Sun et al. [12], demonstrating that streptokinase increased mortality of Group A streptococcal infection in a skin infection model in huPlg transgene mice. Importantly, streptokinase is insensitive to $\alpha_{2} \mathrm{AP}$ inhibition, in contrast with the SAKhuPli complex that is rapidly inactivated by $\alpha_{2}$ AP. Our results confirm previous findings that fibrin protects the SAK-huPli complex from inactivation; and a similar protective effect was noted from bacterial surfaces $[8,32,33]$. This may explain why SAK-mediated plasmin has more localized effects compared to streptokinase-induced plasmin. SAK-induced proteolysis is thus confined to the immediate surroundings of the site of infection, where high concentrations of fibrin and bacteria prevent inactivation, but is rapidly neutralized further away from the abscess site. In contrast, streptokinase-activated plasmin may have a larger potential for systemic effect because of its resistance to $\alpha_{2} \mathrm{AP}$.

To explore whether inhibition by $\alpha_{2} \mathrm{AP}$ accounts for the more localized effect of SAK compared to streptokinase, we studied the impact of the genetic absence of $\alpha_{2} \mathrm{AP}$ on the characteristics of $S$. aureus skin infection. Indeed, $\alpha_{2} \mathrm{AP} \mathrm{KO}$ was associated with larger lesion sizes, compatible with a protective role of $\alpha_{2} \mathrm{AP}$ in tempering the proteolytic effect of SAK-mediated plasmin. The larger lesion size in $\alpha_{2} \mathrm{AP} \mathrm{KO} /$ null mice, lacking huPlg expression, is likely explained by activation of murine plasminogen, bound to surface plasminogen receptors of S. aureus, by host plasminogen activators. Different surface plasminogen receptors have been described in S. aureus, such as $\alpha$-enolase, inosine 5'-monophosphate dehydrogenase, ribonucleotide reductase subunit 2, triose phosphate isomerase, surface immunoglobulin-binding protein and extracellular fibrinogen-binding protein [33-35]. These surface plasminogen receptors are not selective for huPlg and constitute a common theme across different bacterial and fungal organisms for the degradation of extracellular matrix and immune evasion $[35,36]$. The resulting surfacebound plasmin activity is less sensitive to inhibition by plasma protease inhibitors, hence a slower but consistently larger expansion of the lesion occurs in the $\alpha_{2} \mathrm{AP} \mathrm{KO} /$ null group compared to $\mathrm{WT} /$ null controls. The role of host $\alpha_{2} \mathrm{AP}$ in limiting bacterial spreading was confirmed in additional experiments where a SAK-negative strain (S. aureus LS-1 EP) was used to infect $\alpha_{2} \mathrm{AP}$ KO and $\alpha_{2} \mathrm{AP}$ WT mice. As $\alpha_{2} \mathrm{AP}$ gene deficiency does not impair fibrin generation, the initial fibrin deposition surrounding the abscess was comparable in both groups. However, at a later time point the absence of the main plasmin inhibitor led to increased 


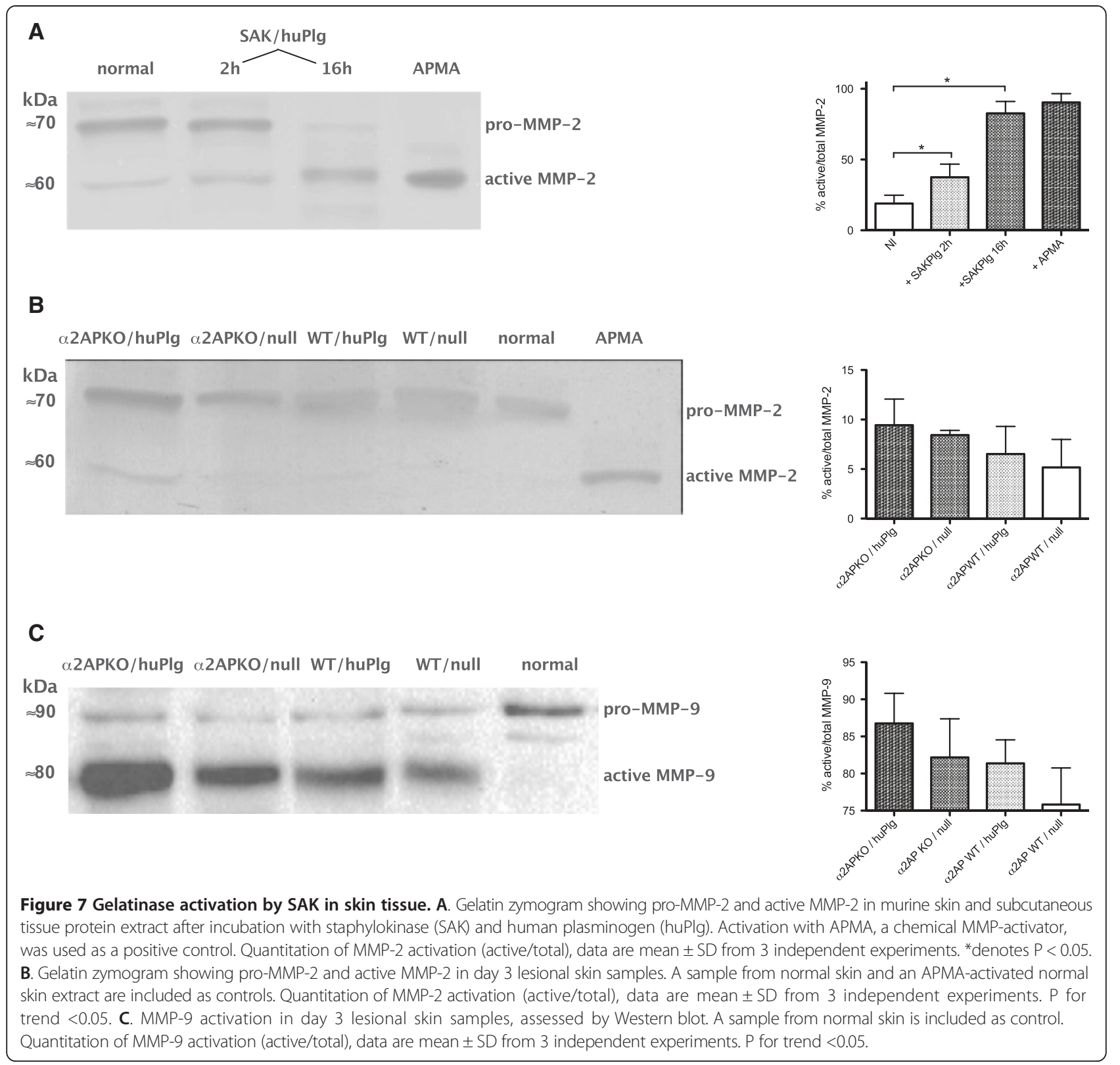

dissolution of the peripheral fibrin sheath. Although there was a trend towards higher numbers of systemic infection in $\alpha_{2}$ AP KO mice (4/25 vs $1 / 29$ WT mice), we could not demonstrate a strong effect of $\alpha_{2} \mathrm{AP}$ KO on systemic spreading. Although $\alpha_{2} \mathrm{AP}$ is the predominant plasmin inhibitor, other plasma inhibitors of fibrinolysis such as alpha-2-macroglobulin may explain the absence of systemic spread in $\alpha_{2} \mathrm{AP} \mathrm{KO} /$ huPlg mice [32].

Interestingly, we also observed increased bacterial loads in the presence of huPlg and/or in the absence of $\alpha_{2} \mathrm{AP}$, demonstrating that bacterial induced plasmin generation helps to evade bacterial clearance by the host. It has been shown previously that SAK binds to and inactivates human defensins, part of the innate immune defense against bacteria [37]. SAK-induced plasmin activity can degrade opsonizing complement components IgG and C3b [38], thus protecting $S$. aureus from phagocytosis.

The production of SAK, a highly fibrin-specific plasminogen activator $[7,8]$, is particularly intriguing as $S$. aureus also triggers fibrin formation through coagulase activity. The role of staphylocoagulase-mediated fibrin deposition in abscess formation is well established [3]. S. aureus also possesses different binding proteins which interact with fibrin(ogen) and extracellular matrix proteins [39]. It remains to be resolved how coagulase-mediated fibrin deposition and SAK-mediated fibrinolysis cooperate to promote $S$. aureus virulence. Coagulase activity and the resulting fibrin have been shown to shield $S$. aureus from 
leukocytes, promoting early replication and persistence. In this view, SAK allows $S$. aureus to generate fibrinolytic activity that is protected by both the staphylothrombin- and thrombin-generated fibrin from rapid neutralization by host protease inhibitors. The resulting plasmin activity can degrade the host's fibrin as well as the S. aureus-mediated fibrin and allow subsequent spreading of the growing bacterial colony. How $S$. aureus differentially regulates coagulase and SAK activity remains unknown. Interestingly, SAK expression is under control of the agr quorum sensing system, suggesting that proteolytic activity is modulated by bacterial density [40]. A regulated expression of SAK may also explain the observed decreased virulence of genetically engineered $S$. aureus strains with SAK overproduction, not under control of its own promotor, as continuous and high-level SAK production will interfere with coagulase activity as a central virulence factor of $S$. aureus $[9,10]$.

\section{Conclusions}

We show that SAK-mediated proteolytic activity in $S$. aureus infected skin facilitates local spreading, increases tissue damage of skin and reduces bacterial clearance by the host. The underlying mechanisms involve protection of the SAK-huPli complex associated with fibrin or bacterial surfaces, from rapid inhibition by $\alpha_{2} \mathrm{AP}$. In turn, active SAK-huPli may activate gelatinases, further promoting degradation of the extracellular matrix. Overall, this study shows the role of subversion of the host fibrinolytic system by SAK-producing $S$. aureus in migration through tissue barriers.

\section{Methods}

\section{Bacterial strains}

All animal experiments were performed with S. aureus Xen36 (Caliper Life Sciences, Hopkinton, USA), a bioluminescent strain derived from the parental strain $S$. aureus ATCC 49525 (Wright), a clinical isolate from a patient with bacteremia. S. aureus Xen36 possesses a stable copy of the modified Photorhabdus luminescens luxABCDE operon at a single integration site on a native plasmid.

Clinical strains were collected from patients at the University Hospitals Leuven and originated from either skin infection or bacteremia secondary to a skin infection with $S$. aureus. Laboratory strains included $S$. aureus Newman and 3 different congenic $S$. aureus LS-1 variants with different SAK expression (LS-1 EP, LS-1 sak and LS-1 spasak) [9].

All strains were stored in Brain Heart Infusion (BHI) with glycerol at $-80^{\circ} \mathrm{C}$. Before use, strains were grown overnight in Tryptic Soy Broth (TSB) at $37^{\circ} \mathrm{C}$ in aerobic conditions. For subcutaneous infection, overnight cultures were washed twice with PBS and diluted in PBS to an optical density at $600 \mathrm{~nm}\left(\mathrm{OD}_{600}\right)$ of 2.0 , corresponding to $2 \times 10^{9}$ CFU (colony forming units) $/ \mathrm{mL}$. CFU counts were confirmed by quantitative plating of the inoculum for each experiment. SAK production was confirmed in the supernatant of overnight cultures using an in-house developed sandwich ELISA (MA-S20D11 + MA-S25F6/PA-RaSTAN ELISA).

\section{Animal experiments}

All animal experimental procedures were approved by the Ethics Committee of the KU Leuven.

\section{Mouse strains}

$\alpha_{2}$ AP knock-out mice in C57BL/6 - S129Vj background and their littermate wild type controls were used [41].

\section{Adenoviral expression of huPlg}

Because of the selectivity of SAK for huPlg, we studied the role of SAK in a subcutaneous $S$. aureus infection model after huPlg overexpression through adenoviral gene transfer. An E1E3E4-deleted adenoviral vector inducing hepatocyte-specific expression of huPlg (Adplasm) was used. In this vector, the expression of huPlg is under control of the alpha-1-antitrypsin promoter and four copies of the human Apo E enhancer [42]. Adnull, a similar adenoviral vector lacking an expression cassette was used as control [43].

Male mice of 5-9 weeks were injected via the tail vein with $5 \times 10^{10}$ particles of either Adplasm or Adnull vector, 7-11 days prior to the subcutaneous infection. Hence, 4 different groups of mice were studied, which are identified as $\alpha_{2} \mathrm{AP} \mathrm{KO} / \mathrm{huPlg}, \alpha_{2} \mathrm{AP} \mathrm{KO} /$ null, WT/huPlg and WT/ null, respectively.

\section{Quantification of huPlg}

Plasma concentrations of huPlg were quantitated by ELISA and by a functional test specific for huPlg, allowing measurement of huPlg concentrations in murine plasma. The in-house developed sandwich ELISA, based on the antibodies MA-42B12B4B2D and MA-34D3D10HRP does not cross-react with murine plasminogen. The functional assay is based on the species-selectivity of streptokinase, and measures plasmin generation with a chromogenic substrate (S-2403, Chromogenix, Milano, Italy) after addition of an excess of streptokinase (1000 IU/mL, Streptase, CSL Behring, Marburg, Germany).

Preliminary experiments showed reliable and stable expression of huPlg from day 7 up to 1 month (day 43) after injection of adenoviral vector.

\section{Skin infection model}

Approximately 1 week post adenoviral injection, mice were anesthesized with isoflurane and injected subcutaneously in each flank with $100 \mu \mathrm{L}$ containing $2 \times 10^{8} \mathrm{CFU}$ of $S$. aureus Xen36. Blood samples were collected on citrate $(3.2 \%$ sodiumcitrate, $10 \% \mathrm{vol} / \mathrm{vol}$ ) by retro-orbital puncture, at 
day 0 (before infection) and day 5. At day 10, animals were killed by heart puncture under high dose ketamine/ xylazine anesthesia. Largest diameter (a) and orthogonal diameter $(b)$ of skin lesions were measured with a caliper, and skin lesion areas were calculated $((\pi / 4) a b)$. Lesions were then excised for histological analysis. Dimensions of lesions from left and right flank were averaged per individual mouse. Spleen and kidneys were also collected for analysis of bacterial load.

One mouse died on day 4 in the $\alpha_{2} \mathrm{AP} \mathrm{KO} /$ null group, this subject was not included in analysis.

In a supplementary experiment, to study the effect of host $\alpha_{2} \mathrm{AP}$ in staphylococcal skin infection, this subcutaneous infection model was carried out with SAK-negative $S$. aureus LS-1 EP in $\alpha_{2} \mathrm{AP}$ KO or WT mice without previous adenoviral injection.

\section{Bioluminescence imaging}

Non-invasive follow-up of the local spreading of $S$. aureus Xen36 was performed by means of bioluminescence imaging of the luciferase signal with a cooled CCD camera (IVIS 100, Xenogen, Perkin-Elmer Company, Alameda, USA). Mice were sedated with isoflurane and imaging was performed for each lesion with an exposure time of $60 \mathrm{~s}$. Signal intensity was calculated with Living Image 2.5 analysis software (Xenogen) and denotes photons per second through a defined region of interest (ROI), corresponding to the infectious lesion. The same ROI was used for all infectious lesions in all animals. Preliminary experiments showed a correlation between bioluminescence signal intensity and bacterial load of $S$. aureus Xen36 (Pearson $\mathrm{r}=$ $0.965, \mathrm{P}=0.0001$ ). A fixed threshold was chosen for all images and quantitation of the lesion size (pixels with signal above threshold) was performed with Image J software (Image J, NIH, Bethesda, USA).

\section{Histology}

Paraffin-embedded tissue samples were used to prepare $10 \mu \mathrm{m}$ thick sections. Routine histopathologic stainings with hematoxyllin-eosin or Martius Scarlet Blue (for fibrin) were performed.

\section{Study of plasminogen activation by SAK}

We studied the activation of plasminogen (human, murine, or a mixture of both) by SAK in the absence or presence of $\alpha_{2} \mathrm{AP}$, fibrin and $S$. aureus bacteria. Human and murine plasminogen were isolated from plasma by lysine Sepharose affinity chromatography, as described previously [44]. SAK variant TS-162 was previously described [45]. Murine $\alpha_{2} \mathrm{AP}$ was obtained from Abcam (Cambridge, UK). SAK, $\alpha_{2} \mathrm{AP}$ and plasminogen were diluted in $0.1 \mathrm{M}$ sodium phosphate buffer, $\mathrm{pH} 7.4$, containing $0.05 \mathrm{M} \mathrm{NaCl}$ and $0.01 \%$ Tween. Solid fibrin clots were formed upon addition of bovine thrombin $(1 \mathrm{U} / \mathrm{mL})$ to human fibrinogen
$(200 \mu \mathrm{g} / \mathrm{mL}$ in $0.05 \mathrm{M}$ Tris-HC1 buffer, $\mathrm{pH} 7.4$, containing $0.038 \mathrm{M} \mathrm{NaCl}$ and $0.01 \%$ Tween 80) (Calbiochem, EMD Millipore, Billerica, USA) (30 min, $\left.37^{\circ} \mathrm{C}\right)$. CNBr-digested murine fibrinogen $(\mathrm{Fg}(\mathrm{CNBr}))$ was prepared as published [46]. In some experiments, $S$. aureus bacteria $\left(\mathrm{OD}_{600} 2.0\right.$, $15 \% \mathrm{vol} / \mathrm{vol}$; live or heat-killed at $60^{\circ} \mathrm{C}$ for $1 \mathrm{~h}$ ) were used in the reaction mixture. In this case, bacteria were pelleted by centrifugation before read-out of the absorbance at $405 \mathrm{~nm}\left(\mathrm{~A}_{405}\right)$. Hydrolysis of the chromogenic substrate S-2403 was used to monitor plasmin activity in a Bio-TEK microtiter plate reader (Bio-TEK, Winooski, USA).

\section{Blotting techniques}

Gelatin zymography was used to study activation of the gelatinase subfamily of matrix metalloproteinases (MMPs) by the SAK-human plasmin complex (SAK-huPli). To this end, tissue extracts of skin and subcutaneous tissue from healthy C57BL/6 mice were prepared as described $[47,48]$. Briefly, tissue samples were snap frozen in liquid nitrogen. Protein extraction was performed by homogenization with glass beads in FastPrep24 (MP Biomedicals, Santa Ana, USA) in the presence of extraction buffer (10 mM sodium phosphate, $\mathrm{pH} 7.2$, containing $150 \mathrm{mM} \mathrm{NaCl}, 1 \%$ Triton $\mathrm{X}-100,0.1 \%$ SDS, $0.5 \%$ sodium deoxycholate, and $0.2 \%$ $\mathrm{NaN}_{3}$ ). After centrifugation, the protein concentration of the supernatant was determined with the Bradford assay (Bio-rad, Hercules, USA). The skin extracts were incubated $\left(2 \mathrm{~h}\right.$ or $\left.16 \mathrm{~h}, 37^{\circ} \mathrm{C}\right)$ with a mixture of $1.1 \mu \mathrm{M}$ huPlg and SAK (in a 1:10 molar ratio to huPlg).

Zymographic analysis of gelatinase activity was performed on $10 \%$ Tris-glycine gels containing $0.1 \%$ gelatin (Novex, Life Technologies, Carlsbad, USA).

We used MMP-containing medium from a HT1080 fibrosarcoma cell line (Sigma-Aldrich, St. Louis, USA) and activation by APMA (4-amino-phenyl-mercuric acetate, a chemical MMP-activator, Sigma-Aldrich) as a reference.

Preliminary experiments showed that plasmin also generated a gelatinolytic band on zymography. To irreversibly inactivate plasmin prior to loading, samples were treated with a 100-fold molar excess of D-Val-Phe-Lys-chloromethylketone, dihydrochloride (Sigma-Aldrich) (15 min, room temperature).

The lysis of the substrate gel (area $\times$ intensity) was quantitated by image analysis (Image J) [47].

Western blotting for murine MMP-2 and MMP-9 was performed using a rabbit polyclonal antibody (NB200-193 for MMP-2, Novus Biologicals, Cambridge, UK and ab38898 for MMP-9, Abcam).

\section{Statistical analysis}

All calculations were performed using GraphPad Prism 5.0b (GraphPad Software, San Diego, USA). Data were tested for normality and appropriate tests were used to compare continuous variables between groups ( $\mathrm{t}$-test if 
normal distribution, Mann-Whitney $U$ test if not). For bioluminescence data, values were compared at definite time points with 1-way ANOVA, using t-test or MannWhitney $U$ test as post-test. For comparison of bioluminescence data over different time points and between groups, 2-way ANOVA was used. For plasmin generation experiments, $\mathrm{A}_{405}$ values were compared by repeated measures 1-way ANOVA, using paired t-tests as post-test. Quantitative data from blotting experiments were analyzed for trend using linear regression. P-values $<0.05$ were considered statistically significant. In graphs, *denotes $\mathrm{P}<0.05$, $* \mathrm{P}<0.01$, *** $\mathrm{P}<0.001$.

\section{Additional file}

\section{Additional file 1: Host $a_{2}$-antiplasmin $\left(a_{2} A P\right)$ protects against} extension of $S$. aureus skin infection. Martius Scarlet Blue staining of representative lesions from $\mathrm{a}_{2} \mathrm{AP} K \mathrm{KO}$ and $\mathrm{a}_{2} \mathrm{AP} W \mathrm{WT}$ mice, infected with S. aureus LS-1 EP. In both genotypes, a peripheral zone of fibrin ( $F$, red), surrounding the abscess, can be appreciated on day 1. On day 3 however, less fibrin is observed in the abscess periphery of $\mathrm{a}_{2} \mathrm{AP} \mathrm{KO}$ mice, likely reflecting the disbalance between (normal) fibrin deposition and (uninhibited) fibrinolysis at this later time point. Hence, $a_{2} \mathrm{AP}$ gene deficiency impairs sustained local containment of $S$. aureus infection.

\section{Abbreviations}

S. aureus: Staphylococcus aureus; SAK: staphylokinase; $\mathrm{a}_{2}$ AP: alpha-2-antiplasmin; huPlg: human plasminogen; huPli: human plasmin; muPlg: murine plasminogen; MMP: matrix metalloproteinase.

\section{Competing interests}

The authors declare that they have no competing interests.

\section{Authors' contributions}

MP designed the experiments, analysed and interpreted the data, performed the statistical analysis and wrote the manuscript. TV, LL and JC assisted in experimental design, statistical analysis and in manuscript revision. JK and TJ provided the LS-1 congenic strains and contributed to manuscript revision. BDG prepared the viral vectors and reviewed the manuscript. $M H, R L$ and $P V$ coordinated the research and reviewed the manuscript. All authors read and approved the final manuscript.

\section{Acknowledgements}

This work was supported by a grant of the Research Foundation Flanders (FWO-Vlaanderen, $1110113 \mathrm{~N}$ ). MP, TV and LL are fellows of the FWO, PV is a senior clinical investigator of the FWO.

The authors would like to thank Professer U. Himmelreich and the staff of the MoSAIC core facility of the KU Leuven for assistance in bioluminescence imaging.

We would like to thank Professor J. Verhaegen for collection of clinical strains. We thank K. Cludts, S. Van kerckhoven and M. Lox for skillful technical assistance.

\section{Author details}

${ }^{1}$ Center for Molecular and Vascular Biology, KU Leuven, Herestraat 49, Box 911, Leuven, Belgium. ²Biomedical MRI/Molecular Small Animal Imaging Center, KU Leuven, Herestraat 49, Box 505, Leuven, Belgium. ${ }^{3}$ Department of Rheumatology and Inflammation Research, University of Gothenburg, Guldhedsgatan 10, Box 480, Gothenburg, Sweden.

Received: 23 July 2014 Accepted: 24 November 2014

Published online: 17 December 2014

\section{References}

1. Ray GT, Suaya JA, Baxter R: Microbiology of skin and soft tissue infections in the age of community-acquired methicillin-resistant Staphylococcus aureus. Diagn Microbiol Infect Dis 2013, 76:24-30.

2. Sader HS, Farrell DJ, Jones RN: Antimicrobial susceptibility of Gram-positive cocci isolated from skin and skin-structure infections in European medical centres. Int J Antimicrob Agents 2010, 36:28-32.

3. Vanassche T, Verhaegen J, Peetermans WE, Van Ryn J, Cheng A, Schneewind O, Hoylaerts MF, Verhamme P: Inhibition of staphylothrombin by dabigatran reduces Staphylococcus aureus virulence. J Thromb Haemost 2011, 9:2436-2446.

4. Vanassche $T$, Peetermans $M$, Van Aelst L, Peetermans WE, Verhaegen J, Missiakas D, Schneewind O, Hoylaerts M, Verhamme P: The role of staphylothrombin-mediated fibrin deposition in catheter-related Staphylococcus aureus infections. J Infect Dis 2013, 208:92-100.

5. McAdow M, Kim HK, Dedent AC, Hendrickx AP, Schneewind O, Missiakas DM: Preventing Staphylococcus aureus sepsis through the inhibition of its agglutination in blood. PLOS Pathog 2011, 7:e1002307.

6. Sawai T, Tomono K, Yanagihara K, Yamamoto Y, Kaku M, Hirakata Y, Koga H, Tashiro T, Kohno S: Role of coagulase in a murine model of hematogenous pulmonary infection induced by intravenous injection of Staphylococcus aureus enmeshed in agar beads. Infect Immun 1997, 65:466-471.

7. Collen D: Staphylokinase: a potent, uniquely fibrin-selective thrombolytic agent. Nat Med 1998, 4:279-284.

8. Lijnen HR, Van Hoef B, De Cock F, Okada K, Ueshima S, Matsuo O, Collen D: On the mechanism of fibrin-specific plasminogen activation by staphylokinase. J Biol Chem 1991, 266:11826-11832.

9. Kwiecinski J, Josefsson E, Mitchell J, Higgins J, Magnusson M, Foster T, Jin T, Bokarewa M: Activation of plasminogen by staphylokinase reduces the severity of Staphylococcus aureus systemic infection. J Infect Dis 2010, 202:1041-1049.

10. Kwiecinski J, Jacobsson G, Karlsson M, Zhu X, Wang W, Bremell T, Josefsson E, Jin T: Staphylokinase Promotes the Establishment of Staphylococcus aureus Skin Infections While Decreasing Disease Severity. J Infect Dis 2013, 208:990-9.

11. Lijnen HR, Stassen JM, Vanlinthout I, Fukao H, Okada K, Matsuo O, Collen D: Comparative fibrinolytic properties of staphylokinase and streptokinase in animal models of venous thrombosis. Thromb Haemost 1991, 66:468-473.

12. Sun H, Ringdahl U, Homeister JW, Fay WP, Engleberg NC, Yang AY, Rozek LS, Wang $X$, Sjobring U, Ginsburg D: Plasminogen is a critical host pathogenicity factor for group A streptococcal infection. Science 2004, 305:1283-1286.

13. Khil J, Im M, Heath A, Ringdahl U, Mundada L, Cary Engleberg N, Fay WP: Plasminogen enhances virulence of group A streptococci by streptokinase-dependent and streptokinase-independent mechanisms. J Infect Dis 2003, 188:497-505.

14. Cook SM, Skora A, Walker MJ, Sanderson-Smith ML, McArthur JD: Site-restricted plasminogen activation mediated by group A streptococcal streptokinase variants. Biochem J 2014, 458:23-31.

15. Piechowicz L, Galin'ski J, Garbacz K, Haras K: Bacteriophage analysis of staphylokinase-negative Staphylococcus aureus strains isolated from people. J Basic Microbiol 2010, 50:557-561.

16. Jin T, Bokarewa M, McIntyre L, Tarkowski A, Corey GR, Reller LB, Fowler VG Jr: Fatal outcome of bacteraemic patients caused by infection with staphylokinase-deficient Staphylococcus aureus strains. J Med Microbiol 2003, 52:919-923.

17. Ruotsalainen E, Karden-Lilja M, Kuusela P, Vuopio-Varkila J, Virolainen-Julkunen A, Sarna S, Valtonen V, Jarvinen A: Methicillin-sensitive Staphylococcus aureus bacteraemia and endocarditis among injection drug users and nonaddicts: host factors, microbiological and serological characteristics. J Infect 2008, 56:249-256

18. Luedicke C, Slickers P, Ehricht R, Monecke S: Molecular fingerprinting of Staphylococcus aureus from bone and joint infections. Eur J Clin Microbiol Infect Dis 2010, 29:457-463.

19. Monecke S, Luedicke C, Slickers P, Ehricht R: Molecular epidemiology of Staphylococcus aureus in asymptomatic carriers. Eur J Clin Microbiol Infect Dis 2009, 28:1159-1165.

20. Monecke S, Berger-Bachi B, Coombs G, Holmes A, Kay I, Kearns A, Linde HJ, O'Brien F, Slickers $P$, Ehricht R: Comparative genomics and DNA array-based genotyping of pandemic Staphylococcus aureus strains encoding Panton-Valentine leukocidin. Clin Microbiol Infect 2007, 13:236-249. 
21. van Wamel WJ, Rooijakkers SH, Ruyken M, van Kessel KP, van Strijp JA: The innate immune modulators staphylococcal complement inhibitor and chemotaxis inhibitory protein of Staphylococcus aureus are located on beta-hemolysin-converting bacteriophages. J Bacteriol 2006, 188:1310-1315.

22. Humphreys $H$, Keane $C T$, Hone R, Pomeroy H, Russell RJ, Arbuthnott JP, Coleman DC: Enterotoxin production by Staphylococcus aureus isolates from cases of septicaemia and from healthy carriers. J Med Microbiol 1989, 28:163-172.

23. Katayama Y, Baba T, Sekine M, Fukuda M, Hiramatsu K: Beta-hemolysin promotes skin colonization by Staphylococcus aureus. J Bacteriol 2013 195:1194-1203.

24. Resch G, Francois P, Morisset D, Stojanov M, Bonetti EJ, Schrenzel J, Sakwinska O, Moreillon P: Human-to-bovine jump of Staphylococcus aureus CC8 is associated with the loss of a beta-hemolysin converting prophage and the acquisition of a new staphylococcal cassette chromosome. PLOS ONE 2013, 8:e58187.

25. Gladysheva IP, Turner RB, Sazonova IY, Liu L, Reed GL: Coevolutionary patterns in plasminogen activation. Proc Natl Acad Sci U S A 2003, 100:9168-9172.

26. Kim SH, Chun HS, Han MH, Park NY, Suk K: A novel variant of staphylokinase gene from Staphylococcus aureus ATCC 29213. Thromb Res 1997, 87:387-395.

27. Sako T, Sawaki S, Sakurai T, Ito S, Yoshizawa Y, Kondo I: Cloning and expression of the staphylokinase gene of Staphylococcus aureus in Escherichia coli. Mol Gen Genet 1983, 190:271-277.

28. Behnke D, Gerlach D: Cloning and expression in Escherichia coli, Bacillus subtilis, and Streptococcus sanguis of a gene for staphylokinase-a bacterial plasminogen activator. Mol Gen Genet 1987, 210:528-534.

29. Coleman DC, Sullivan DJ, Russell RJ, Arbuthnott JP, Carey BF, Pomeroy HM: Staphylococcus aureus bacteriophages mediating the simultaneous lysogenic conversion of beta-lysin, staphylokinase and enterotoxin A: molecular mechanism of triple conversion. J Gen Microbio/ 1989 135:1679-1697.

30. Sumby $P$, Waldor MK: Transcription of the toxin genes present within the Staphylococcal phage phiSa3ms is intimately linked with the phage's life cycle. J Bacterio/ 2003, 185:6841-6851.

31. Lijnen HR: Plasmin and matrix metalloproteinases in vascular remodeling. Thromb Haemost 2001, 86:324-333.

32. Collen D: Identification and some properties of a new fast-reacting plasmin inhibitor in human plasma. Eur J Biochem 1976, 69:209-216.

33. Molkanen T, Tyynela J, Helin J, Kalkkinen N, Kuusela P: Enhanced activation of bound plasminogen on Staphylococcus aureus by staphylokinase. FEBS Lett 2002, 517:72-78.

34. Furuya $H$, Ikeda R: Interaction of triosephosphate isomerase from Staphylococcus aureus with plasminogen. Microbiol Immunol 2011, 55:855-862.

35. Koch TK, Reuter M, Barthel D, Bohm S, van den Elsen J, Kraiczy P, Zipfel PF, Skerka C: Staphylococcus aureus proteins Sbi and Efb recruit human plasmin to degrade complement C3 and C3b. PLOS ONE 2012, 7:e47638.

36. Souza NM, Vieira ML, Alves IJ, de Morais ZM, Vasconcellos SA, Nascimento AL: Lsa30, a novel adhesin of Leptospira interrogans binds human plasminogen and the complement regulator C4bp. Microb Pathog 2012, 53:125-134

37. Jin T, Bokarewa M, Foster T, Mitchell J, Higgins J, Tarkowski A: Staphylococcus aureus resists human defensins by production of staphylokinase, a novel bacterial evasion mechanism. J Immunol 2004, 172:1169-1176.

38. Rooijakkers SH, van Wamel WJ, Ruyken M, van Kessel KP, van Strijp JA: Anti-opsonic properties of staphylokinase. Microbes Infect 2005, 7:476-484.

39. Foster TJ, Hook M: Surface protein adhesins of Staphylococcus aureus. Trends Microbiol 2003, 48:1429-49.

40. Novick RP: Autoinduction and signal transduction in the regulation of staphylococcal virulence. Mol Microbiol 2003, 48:1429-1449.

41. Lijnen HR: Gene targeting in hemostasis. Alpha2-antiplasmin. Front Biosc 2001, 6:D239-247.

42. Feng $Y$, Jacobs F, Van Craeyveld E, Lievens J, Snoeys J, Van Linthout S, De Geest B: The impact of antigen expression in antigen-presenting cells on humoral immune responses against the transgene product. Gene Ther 2010, 17:288-293.
43. Van Linthout S, Lusky M, Collen D, De Geest B: Persistent hepatic expression of human apo A-I after transfer with a helper-virus independent adenoviral vector. Gene Ther 2002, 9:1520-1528.

44. Deutsch DG, Mertz ET: Plasminogen: purification from human plasma by affinity chromatography. Science 1970, 170:1095-1096.

45. Verhamme P, Goossens G, Maleux G, Collen D, Stas M: A dose-finding clinical trial of staphylokinase SY162 in patients with long-term venous access catheter thrombotic occlusion. J Thromb Thrombolysis 2007, 24:1-5.

46. Holvoet P, Lijnen HR, Collen D: A monoclonal antibody preventing binding of tissue-type plasminogen activator to fibrin: useful to monitor fibrinogen breakdown during t-PA infusion. Blood 1986, 67:1482-1487.

47. Van Hul M, Lijnen HR: Effect of weight loss on gelatinase levels in obese mice. Clin Exp Pharmacol Physiol 2011, 38:647-649.

48. Van Hul M, Lijnen HR: A functional role of gelatinase $A$ in the development of nutritionally induced obesity in mice. J Thromb Haemost 2008, 6:1198-1206.

doi:10.1186/s12866-014-0310-7

Cite this article as: Peetermans et al: Plasminogen activation by staphylokinase enhances local spreading of S. aureus in skin infections. BMC Microbiology 2014 14:310.

\section{Submit your next manuscript to BioMed Central and take full advantage of:}

- Convenient online submission

- Thorough peer review

- No space constraints or color figure charges

- Immediate publication on acceptance

- Inclusion in PubMed, CAS, Scopus and Google Scholar

- Research which is freely available for redistribution

Submit your manuscript at www.biomedcentral.com/submit
C Biomed Central 